\title{
Oral cow's milk immunotherapy: clinical and serological data in long-term follow up
}

Paloma Poza Guedes*, Ruperto González Pérez, Inmaculada Sánchez Machín, Victor Matheu Delgado

From Food Allergy and Anaphylaxis Meeting 2014

Dublin, Ireland. 9-11 October 2014

\section{Rationale}

Oral food inmunotherapy is a promising therapeutic aproach in patients with persistent cow's milk allergy (CMA). Although it seems that these protocols show a better outcome in patients with "milder" symptoms (i.e. non anaphylactic reactions) there are controversial results in highly sensitized subjects.

\section{Methods}

We select patients with persistent CMA and severe uncontrolled anaphylactic symptoms despite a correct restrictive diet. We performed a two-day desensitization procedure at the Pediatric Critical Care Unit in our Institution. The second phase was weekly scheduled in the Outpatient clinic to reach a final cumulative dose of $250 \mathrm{ml}$ of undiluted milk. Clinical and serological date were collected every six month for a five-year period.

\section{Results}

Fifteen children (2-16 y.o.) were included. All children reached the final dose of $250 \mathrm{ml}$ of undiluted milk in less than ten weeks. Clinical follow-up every 6 months remained during 5 years to register all adverse reactions and possible factors involved. Serological changes were obtained every six months during the subsequent five years, including specific IgE and IgG4.

\section{Conclusion}

Anaphylactic CMA patients may benefit from rush oral Cow's Milk immunotherapy. Clinical and serological changes have been found both at early and long-term follow-up. Several factors were involved in reactions for temporary loss of tolerance.

Published: 30 March 2015

Santa Cruz de Tenerife, Canary Islands, Spain
doi:10.1186/2045-7022-5-S3-P158

Cite this article as: Poza Guedes et al:: Oral cow's milk immunotherapy: clinical and serological data in long-term follow up. Clinical and Translational Allergy 2015 5(Suppl 3):P158.
Submit your next manuscript to BioMed Central and take full advantage of:

- Convenient online submission

- Thorough peer review

- No space constraints or color figure charges

- Immediate publication on acceptance

- Inclusion in PubMed, CAS, Scopus and Google Scholar

- Research which is freely available for redistribution
() Biomed Central 